\title{
Effects of preoperative oral administration of glucose solution combined with postoperative probiotics on inflammation and intestinal barrier function in patients after colorectal cancer surgery
}

\author{
QINGWEN XU*, PENGYUAN XU*, YUNYUN CEN and WEIMING LI \\ Second Ward of Gastrointestinal Surgery, The Second Affiliated Hospital of Kunming Medical University, \\ Kunming, Yunnan 650101, P.R. China
}

Received November 27, 2018; Accepted April 5, 2019

DOI: $10.3892 / \mathrm{ol} .2019 .10336$

\begin{abstract}
The effects of preoperative oral administration of glucose solution combined with postoperative probiotics on inflammation and intestinal barrier function in patients after colorectal cancer surgery were observed. Sixty patients treated and scheduled to undergo radical resection of colorectal cancer in The Second Affiliated Hospital of Kunming Medical University from March 2017 to December 2017 were selected and randomly divided into the glucose solution group $(n=30)$ and combined probiotics group $(n=30)$. Patients in both groups took orally $12.5 \%$ glucose solution before surgery, and those in the combined probiotics group received bifidus-triple viable preparation every day for 7 consecutive days. Changes in endotoxin, insulin-like growth factor-I (IGF-I) concentration, white blood cell count (WBC), C-reactive protein (CRP), D-lactic acid and urinary lactulose/mannitol (L/M) were detected before surgery and at 1,3 and 7 days after surgery. The general condition was observed and changes in intestinal florae were compared between the two groups. The body temperature was measured every $4 \mathrm{~h}$ with an electronic thermometer, and the duration of fever was recorded (from the first day after operation to the time with normal body temperature after operation, axillary temperature $<37.4^{\circ} \mathrm{C}$ ), and the average heart rate was recorded by the ECG monitor. In addition, the time of the first anal exsufflation (the time from the beginning of the operation to the first anal exsufflation) was recorded. In the combined probiotics group, the plasma endotoxin, IGF-I concentration, D-lactic acid and urinary L/M levels were significantly lower
\end{abstract}

Correspondence to: Dr Weiming Li, Second Ward of Gastrointestinal Surgery, The Second Affiliated Hospital of Kunming Medical University, 360 Dianmian Avenue, Kunming, Yunnan 650101, P.R. China

E-mail: 1189168521@163.com

*Contributed equally

Key words: glucose solution, probiotics, after colorectal cancer surgery, inflammation, intestinal barrier function than those in the glucose solution group $(\mathrm{P}<0.05)$. Moreover, the duration of postoperative fever, average heart rate at 7 days after surgery as well as WBC and CRP clinical indexes were obviously shorter and lower in the combined probiotics group than those in the glucose solution group $(\mathrm{P}<0.05)$. Therefore, the combined application of probiotics after surgery can effectively improve the imbalance of intestinal flora. In conclusion, preoperative oral administration of glucose solution combined with postoperative probiotics can improve the intestinal barrier function after colorectal cancer surgery, and benefit the recovery of early inflammatory response after surgery.

\section{Introduction}

Radical resection of colorectal cancer is a highly-traumatic abdominal surgery, which often directly leads to excessive intestinal stress response (1), intestinal mucosal barrier dysfunction, increase in permeability and translocation of pathogenic bacteria and endotoxin, eventually resulting in expanded infection threatening life. As one of the adjuvant treatment means of rapid rehabilitation, the preoperative supplement of carbohydrate can alleviate the surgery-induced stress response to a certain extent (2), the clinical effect, however, is not significant. Some studies have demonstrated that probiotics are able to protect the intestinal mucosal barrier and improve the imbalance of intestinal flora, and its role in the postoperative rehabilitation therapy has attracted increasing attention (3). In this study, the effects of preoperative oral administration of glucose solution combined with postoperative probiotics on early inflammatory response, intestinal barrier function and postoperative infective complications in patients after colorectal cancer surgery were observed.

\section{Patients and methods}

General data. A total of 60 patients treated and scheduled to undergo radical resection of colorectal cancer in The Second Affiliated Hospital of Kunming Medical University (Kunming, China) from March 2017 to December 2017 were selected and randomly divided into the glucose solution group $(n=30)$ and the combined probiotics group $(n=30)$. In the glucose solution 
Table I. Changes in endotoxin and IGF-I levels in both groups.

\begin{tabular}{llccrc}
\hline Items & \multicolumn{1}{c}{ Groups } & $\begin{array}{c}\text { Before } \\
\text { surgery }\end{array}$ & $\begin{array}{c}1 \text { day } \\
\text { after surgery }\end{array}$ & $\begin{array}{c}3 \text { days } \\
\text { after surgery }\end{array}$ \\
\hline Endotoxin $\left(\mathrm{pg} \cdot \mathrm{ml}^{-1}\right)$ & Combined probiotics & $2.25 \pm 0.05$ & $2.33 \pm 0.09$ & $2.62 \pm 0.40$ & $2.40 \pm 0.16$ \\
& Glucose solution & $2.40 \pm 0.25$ & $2.83 \pm 0.55^{\mathrm{a}}$ & $2.98 \pm 0.54^{\mathrm{a}}$ & $2.58 \pm 0.19$ \\
IGF-I $\left(\mu \mathrm{g} \cdot \mathrm{l}^{-1}\right)$ & Glucose solution & $99.17 \pm 62.16$ & $89.65 \pm 35.06$ & $122.33 \pm 54.78$ & $113.95 \pm 63.12$ \\
& Combined probiotics & $94.15 \pm 56.61$ & $54.62 \pm 25.39^{\mathrm{a}}$ & $91.15 \pm 39.92^{\mathrm{a}}$ & $82.04 \pm 40.69^{\mathrm{a}}$
\end{tabular}

${ }^{\text {a }}<0.05$ in the comparison between the two groups. IGF-I, insulin-like growth factor-I.

group, 18 cases were male and 12 cases were female, aged $62.35 \pm 13.71$ years. In the combined probiotics group, there were 20 males and 10 females aged $61.03 \pm 15.28$ years. Patients underwent various preoperative examinations and were definitely diagnosed via pathological examination. Exclusion criteria were: patients with severe organ dysfunction, diabetes mellitus, delayed gastric emptying or other surgical contraindications. General data, such as sex and age, were comparable between the two groups. Before this study, all patients or guardians signed the informed consent.

The study was approved by the Ethics Committee of The Second Affiliated Hospital of Kunming Medical University.

Methods. Patients in both groups orally took $12.5 \%$ glucose solution before surgery, and those in the combined probiotics group received bifidus-triple viable preparation (Inner Mongolia Shuangqi Pharmaceutical Co., Ltd., Inner Mongolia, China) every day for 7 consecutive days. After surgery, patients were treated with nutritional support, anti-infection and prevention of stress ulcer.

Detection indexes. The following indexes were detected at 1 day before surgery and at 1, 3 and 7 days after surgery. The serum endotoxin and insulin-like growth factor-I (IGF-I) were detected using the Multiskan FC full-automatic microplate reader (Molecular Devices, LLC, Sunnyvale, CA, USA). The serum D-lactic acid was detected using the ultraviolet-visible spectrophotometer (Thermo Fisher Scientific, Inc., Waltham, MA, USA). The midstream urinary lactulose/mannitol ( $\mathrm{L} / \mathrm{M})$ concentration in the morning was measured using the LC2000 high-performance liquid chromatograph (Hitachi, Tokyo, Japan). White blood cell count (WBC) and C-reactive protein (CRP) were detected using the Labospect003 full-automatic biochemical analyzer (Hitachi). A totla of $200 \mathrm{mg}$ fresh feces samples in two groups were kept in aseptic bag and stored in refrigerator at $-80^{\circ} \mathrm{C}$. Total DNA in fecal samples was extracted by QIAamp DNAStool MiniKit extraction kit (Qiagen, Dusseldorf, Germany) according to its specifications. The copy number of intestinal flora in faeces before surgery and at 7 days after surgery was detected using the Thermal Cyclers quantitative SYBR-Green PCR instrument (Thermo Fisher Scientific, Inc.). The specific gene 16SrRNA of bacterial species was selected as the amplification region. The specific reaction procedure was as follows: pre-denaturation at $95^{\circ} \mathrm{C}$ for $5 \mathrm{~min}$, denaturation at $95^{\circ} \mathrm{C}$ for $30 \mathrm{sec}$, annealing for $40 \mathrm{sec}$, extension at $60^{\circ} \mathrm{C}$ for $30 \mathrm{sec}, 40$ cycles in total. Then the extension at $72^{\circ} \mathrm{C}$ for $5 \mathrm{~min}$. Intestinal bacterial primer sequences and annealing temperatures were as follows: Bacillus bifidus: forward, 5'-GGGTGGTAATGCCCGGATG-3' and reverse, 5'-TAAGCCATGGACTTTCACACC-3'; 59 ${ }^{\circ} \mathrm{C}$; Escherichia coli: forward, 5'-CATTGACGTTACCCGCAGAAGAAGC-3' and reverse, 5'-CTCTACGAGACTCAAGCTTGC-3'; 64 ${ }^{\circ}$; Lactic acid bacteria: forward, 5'-AGCAGTAGGGAATCTTCCA-3' and reverse, 5'-ATTYCACCGCTACACATG-3'; $58^{\circ} \mathrm{C}$; Enterococcus: forward, 5'-AACCTACCCATCAGAGGG-3' and reverse, 5'-GACGTTCAGTTACTAACG-3'; 57 ${ }^{\circ} \mathrm{C}$. The experimental results were analyzed using the $2^{-\Delta \Delta \mathrm{Cq}}$ method (4).

The body temperature was measured every $4 \mathrm{~h}$ with an electronic thermometer, and the duration of fever was recorded (from the first day after operation to the time with normal body temperature after operation, axillary temperature $<37.4^{\circ} \mathrm{C}$ ), and the average heart rate was recorded by the ECG monitor. In addition, the time of the first anal exsufflation (the time from the beginning of the operation to the first anal exsufflation) was recorded.

Statistical analysis. Statistical Product and Service Solutions 20.0 software (SPSS, Inc., Chicago, IL, USA) was used for statistical analysis. Measurement data were presented as mean \pm standard deviation (mean \pm SD). ANOVA and Dunnett's post hoc test was used for multiple comparisons. $\mathrm{P}<0.05$ was considered to indicate a statistically significant difference.

\section{Results}

Comparison of endotoxin and IGF-I levels before and after surgery between the two groups. The endotoxin level was increased compared with that before surgery in both groups and was increased more significantly in the glucose solution group than that in the combined probiotics group. There were statistically significant differences at 1 and 3 days after surgery between the two groups $(\mathrm{P}<0.05)$. The IGF-I level was decreased in both groups and declined more significantly in the combined probiotics group than that in the glucose solution group. There were statistically significant differences at 1,3 and 7 days after surgery between the two groups. The above results indicate that the preoperative application of glucose combined with postoperative supplement of probiotics can inhibit the decline in IGF-I, accelerate the removal of endotoxin and protect the intestinal mucosal barrier function (Table I). 
Table II. CRP and WBC before and after surgery in both groups.

\begin{tabular}{|c|c|c|c|c|c|}
\hline Items & Groups & $\begin{array}{l}\text { Before } \\
\text { surgery }\end{array}$ & $\begin{array}{c}1 \text { day } \\
\text { after surgery }\end{array}$ & $\begin{array}{c}3 \text { days } \\
\text { after surgery }\end{array}$ & $\begin{array}{c}7 \text { days } \\
\text { after surgery }\end{array}$ \\
\hline \multirow[t]{2}{*}{$\mathrm{WBC}\left(\mathrm{x} 10^{9} \cdot 1^{-1}\right)$} & Glucose solution & $4.2 \pm 0.5$ & $15.4 \pm 2.3$ & $12.8 \pm 1.5$ & $7.1 \pm 1.3$ \\
\hline & Combined probiotics & $4.3 \pm 0.5$ & $15.0 \pm 2.1$ & $8.5 \pm 1.1^{\mathrm{a}}$ & $5.6 \pm 0.9^{\mathrm{a}}$ \\
\hline \multirow[t]{2}{*}{$\mathrm{CRP}\left(\mathrm{mg} \cdot \mathrm{l}^{-1}\right)$} & Glucose solution & $6.3 \pm 0.4$ & $90.1 \pm 10.5$ & $69.8 \pm 9.2$ & $46.7 \pm 5.3$ \\
\hline & Combined probiotics & $6.5 \pm 0.6$ & $86.2 \pm 11.4$ & $53.0 \pm 7.7^{\mathrm{a}}$ & $20.2 \pm 4.4^{\mathrm{a}}$ \\
\hline
\end{tabular}

${ }^{\text {a }}<0.05$ in the comparison between the two groups. CRP, C-reactive protein; WBC, white blood cell count.

Comparison of D-lactic acid and urinary L/M levels before and after surgery between the two groups. The serum D-lactic acid and urinary L/M levels were increased first and then decreased after surgery in both groups, and they declined more obviously in the combined probiotics group than those in the glucose solution group. Differences were statistically significant at 7 days after surgery between the two groups $(\mathrm{P}<0.05)$. The above results suggest that probiotics are beneficial in reducing intestinal mucosal damage and permeability (Figs. 1 and 2).

Comparison of CRP and WBC before and after surgery between the two groups. The CRP level and WBC were increased first and then gradually decreased to the normal range after surgery in both groups, and they declined more obviously in the combined probiotics group than those in the glucose solution group. Differences were statistically significant at 3 and 7 days after surgery between the two groups $(\mathrm{P}<0.05)$. The above results indicate that probiotics can improve the systemic inflammatory response (Table II).

Changes in intestinal florae before and after surgery in both groups. Results of quantitative PCR revealed that the copy numbers of Bifidobacteria and Lactobacillus were decreased after surgery in both groups compared with those before surgery, and they declined more remarkably in the glucose solution group than those in the combined probiotics group. Besides, the copy numbers of Escherichia coli and Enterococcus faecalis were increased, and they were increased more remarkably in the glucose solution group than those in the combined probiotic group. There were statistically significant differences between the two groups $(\mathrm{P}<0.05)$. The above results indicate that the postoperative supplement of probiotics can significantly improve the intestinal microecological environment and strengthen the intestinal mucosal barrier function (Table III).

Comparison of the postoperative general condition between the two groups. It was found after observation for 1 week that the incidence rates of incision infection and hypoproteinemia were similar in both groups $(\mathrm{P}>0.05)$. The duration of postoperative fever, average heart rate at 7 days after surgery and first exhaust time were shorter and lower in the combined probiotics group than those in the glucose solution group $(\mathrm{P}<0.05)($ Table IV).

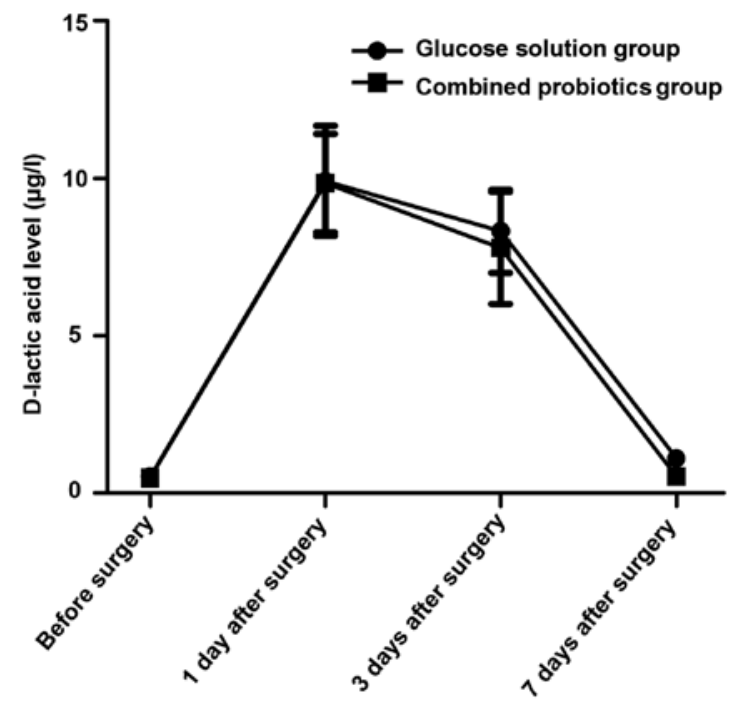

Figure 1. Changes in the serum D-lactic acid level in both groups.

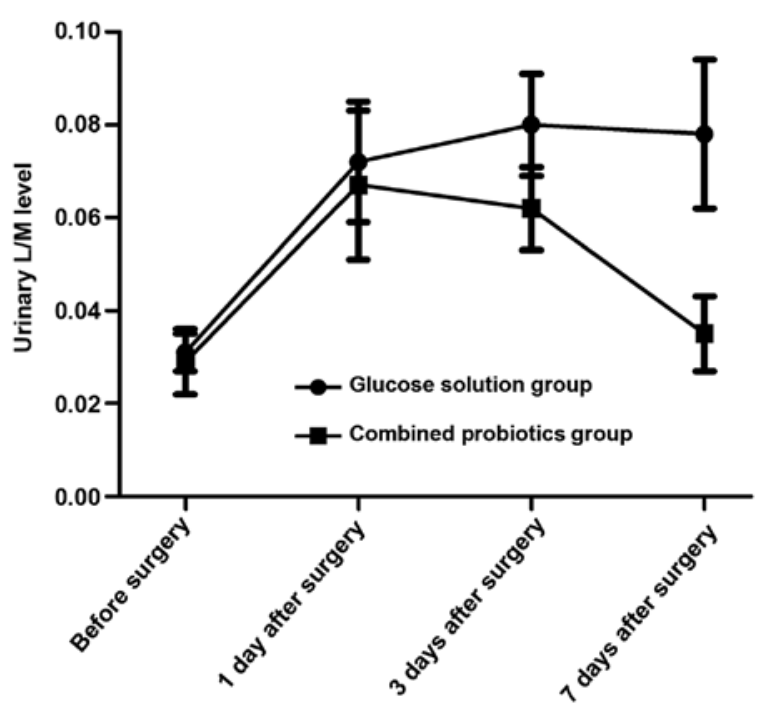

Figure 2. Changes in the urinary L/M level in both groups. L/M, lactulose/mannitol.

\section{Discussion}

According to a number of studies, it has been confirmed that the surgical trauma-induced stress response directly 
Table III. Comparison of intestinal florae before and after surgery in both groups.

\begin{tabular}{llcccc}
\hline Groups & \multicolumn{1}{c}{ Time } & $\begin{array}{c}\text { Bifidobacteria } \\
\text { (copies/g) }\end{array}$ & $\begin{array}{c}\text { Lactobacillus } \\
\text { (copies/g) }\end{array}$ & $\begin{array}{c}\text { Escherichia coli } \\
\text { (copies/g) }\end{array}$ & $\begin{array}{c}\text { Enterococcus faecalis } \\
\text { (copies/g) }\end{array}$ \\
\hline Glucose solution & Before surgery & $9.5 \pm 0.5$ & $9.2 \pm 0.8$ & $8.1 \pm 0.6$ & $8.1 \pm 0.7$ \\
& 7 days after surgery & $8.1 \pm 0.6$ & $5.6 \pm 0.6$ & $9.8 \pm 0.8$ & $9.6 \pm 0.8$ \\
Combined probiotics & Before surgery & $9.4 \pm 0.6$ & $9.1 \pm 0.9$ & $8.2 \pm 0.4$ & $8.1 \pm 0.6$ \\
& 7 days after surgery & $8.5 \pm 0.5^{\mathrm{a}}$ & $7.9 \pm 0.6^{\mathrm{a}}$ & $9.3 \pm 0.7^{\mathrm{a}}$ & $9.0 \pm 0.9^{\mathrm{a}}$ \\
\hline
\end{tabular}

${ }^{\mathrm{a}} \mathrm{P}<0.05$ in the comparison between the two groups.

Table IV. Comparison of the postoperative general condition between the two groups at 7 days after surgery.

\begin{tabular}{lcccc}
\hline Groups & $\begin{array}{c}\text { Average } \\
\text { heart rate }\end{array}$ & $\begin{array}{c}\text { Incision } \\
\text { infection (\%) }\end{array}$ & $\begin{array}{c}\text { Duration of } \\
\text { Hypoproteinemia (\%) }\end{array}$ & $\begin{array}{c}\text { First exhaust } \\
\text { postoperative fever (days) }\end{array}$ \\
\hline Glucose solution & $102.83 \pm 8.36$ & 10.8 & 7.6 & $6.07 \pm 1.11$ \\
Combined probiotics & $87.46 \pm 7.01^{\mathrm{a}}$ & 8.1 & 5.5 & $4.08 \pm 0.60^{\mathrm{a}}$ \\
\hline
\end{tabular}

${ }^{a} \mathrm{P}<0.05$ in the comparison between the two groups.

causes damage to the intestinal mucosal barrier, and thus, the intestinal microflora and endotoxin entering the extraintestinal tissues and organs under the increased permeability of intestinal mucosa, are likely to lead to uncontrolled systemic inflammatory response and multiple organ failure (5-8). The intestinal flora, including anaerobe and probiotics, is an important component of the intestinal mucosal barrier, among which probiotics, dominated by Bifidobacteria and Lactobacillus, can effectively resist the growth of harmful bacteria through the biological effect (9). Fundamental research has manifested that probiotics are able to promote the intestinal epithelial growth, increase the mucus secretion, inhibit the intestinal epithelial apoptosis and antioxidant function, and regulate the intestinal immune function (10-12).

Endotoxin is the lipopolysaccharide in the cell wall of G-bacillus, and bacterial as well as endotoxin translocation occur when the intestinal mucosal barrier is damaged by a variety of stimuli, so detecting the endotoxin level in the blood circulation can evaluate the damage to the intestinal mucosal barrier (13). IGF-I can promote the proliferation of intestinal epithelial cells and alleviate endotoxemia after binding to the corresponding receptors in the small intestinal crypt epithelial cells (14-16). Studies have confirmed that the IGF-I level declines under stress states such as surgical trauma $(17,18)$. The endotoxin level was increased compared with that before surgery in both groups, and was increased more significantly in the glucose solution group than that in the combined probiotics group, and there were statistically significant differences at 1 and 3 days after surgery between the two groups $(\mathrm{P}<0.05)$. The IGF-I level was decreased in both groups and declined more significantly in the combined probiotics group than that in the glucose solution group. There were statistically significant differences at 1 , 3 and 7 days after surgery between the two groups. The above results indicate that the preoperative supplement of glucose combined with postoperative supplement of probiotics can inhibit the decline in IGF-I, accelerate the removal of endotoxin and protect the intestinal mucosal barrier function.

D-lactic acid is the metabolite of the innate flora in the digestive tract, and it can be detected in the blood in case of the increased permeability of intestinal mucosa, which may serve as an early index reflecting the intestinal mucosal damage $(19,20)$. Studies on the rat model of acute intestinal ischemia have demonstrated that the longer the duration of ischemia is and the more serious the damage to the intestinal mucosal barrier is, the higher the D-lactic acid level will be (19). Besides, urinary L/M is also a commonly-used index for clinical monitoring of intestinal mucosal permeability (21). In this study, the serum D-lactic acid and urinary L/M levels were increased first and then decreased after surgery in both groups, and they declined more obviously in the combined probiotics group than those in the glucose solution group. Differences were statistically significant at 7 days after surgery between the two groups $(\mathrm{P}<0.05)$. The above results suggest that probiotics are beneficial in reducing intestinal mucosal damage and permeability. Furthermore, the intestinal flora indexes were detected. Results of quantitative PCR revealed that the copy numbers of Bifidobacteria and Lactobacillus were decreased after surgery in both groups compared with those before surgery, and they declined more remarkably in the glucose solution group than those in the combined probiotics group. Besides, the copy numbers of Escherichia coli and Enterococcus faecalis were increased, and they were increased more remarkably in the glucose solution group than those in combined probiotics group. There were statistically significant differences between the two groups $(\mathrm{P}<0.05)$. The above results indicate that the postoperative supplement of probiotics can significantly improve the intestinal micro-ecological environment and strengthen the intestinal mucosal barrier function. 
Previous studies have revealed that the treatment combined with probiotics after liver transplantation and other abdominal operations shortens the application time of antibiotics and significantly reduces the incidence rate of infection (22). In this study, the incidence rates of incision infection and hypoproteinemia were similar in both groups $(\mathrm{P}>0.05)$. In the combined probiotics group, however, the duration of postoperative fever and first exhaust time were shorter, the average heart rate at 7 days after surgery was lower, and WBC and CRP clinical indexes reflecting the systemic inflammatory response, were improved more obviously at 7 days after surgery, further proving that probiotics can improve the systemic inflammatory response.

In conclusion, preoperative oral administration of glucose solution combined with postoperative probiotics can improve the intestinal barrier function after colorectal cancer surgery, and benefit the recovery of early inflammatory response after surgery.

\section{Acknowledgements}

Not applicable.

\section{Funding}

No funding was received.

\section{Availability of data and materials}

The datasets used and/or analyzed during the current study are available from the corresponding author on reasonable request.

\section{Authors' contributions}

QX wrote the manuscript. QX and PX recorded the general data of patients. QX, PX and YC were responsible for the patient treatment. WL detected and analyzed the indexes. All authors read and approved the final manuscript.

\section{Ethics approval and consent to participate}

The study was approved by the Ethics Committee of The Second Affiliated Hospital of Kunming Medical University (Kunming, China) and informed consents were signed by the patients or guardians.

\section{Patient consent for publication}

Not applicable.

\section{Competing interests}

The authors declare that they have no competing interests.

\section{References}

1. Bjarnason I, MacPherson A and Hollander D: Intestinal permeability: An overview. Gastroenterology 108: 1566-1581, 1995.

2. Yagci G, Can MF, Ozturk E, Dag B, Ozgurtas T, Cosar A and Tufan T: Effects of preoperative carbohydrate loading on glucose metabolism and gastric contents in patients undergoing moderate surgery: A randomized, controlled trial. Nutrition 24: 212-216, 2008 .
3. Klarin B, Johansson ML, Molin G, Larsson A and Jeppsson B: Adhesion of the probiotic bacterium Lactobacillus plantarum $299 \mathrm{v}$ onto the gut mucosa in critically ill patients: A randomised open trial. Crit Care 9: R285-R293, 2005.

4. Livak KJ and Schmittgen TD: Analysis of relative gene expression data using real-time quantitative PCR and the 2(-Delta Delta C(T)) method. Methods 25: 402-408, 2001.

5. Madara JL: Maintenance of the macromolecular barrier at cell extrusion sites in intestinal epithelium: Physiological rearrangement of tight junctions. J Membr Biol 116: 177-184, 1990.

6. Meddings JB and Swain MG: Environmental stress-induced gastrointestinal permeability is mediated by endogenous glucocorticoids in the rat. Gastroenterology 119: 1019-1028, 2000.

7. Deitch EA: The role of intestinal barrier failure and bacterial translocation in the development of systemic infection and multiple organ failure. Arch Surg 125: 403-404, 1990

8. Söderholm JD and Perdue MH: Stress and gastrointestinal tract. II. Stress and intestinal barrier function. Am J Physiol Gastrointest Liver Physiol 280: G7-G13, 2001.

9. Schrezenmeir J and de Vrese M: Probiotics, prebiotics, and synbiotics - approaching a definition. Am J Clin Nutr 73 (2 Suppl): 361S-364S, 2001.

10. Ménard S, Laharie D, Asensio C, Vidal-Martinez T, Candalh C, Rullier A, Zerbib F, Mégraud F, Matysiak-Budnik T and Heyman M: Bifidobacterium breve and Streptococcus thermophilus secretion products enhance Thelper 1 immune response and intestinal barrier in mice. Exp Biol Med (Maywood) 230: 749-756, 2005.

11. Peña JA, Rogers AB, Ge Z, Ng V, Li SY, Fox JG and Versalovic J: Probiotic Lactobacillus spp. diminish Helicobacter hepaticus-induced inflammatory bowel disease in interleukin10-deficient mice. Infect lmmun 73: 912-920, 2005.

12. Gaudier E, Michel C, Segain JP, Cherbut C and Hoebler C: The VSL\# 3 probiotic mixture modifies microflora but does not heal chronic dextran-sodium sulfate-induced colitis or reinforce the mucus barrier in mice. J Nutr 135: 2753-2761, 2005.

13. Buttenschoen K, Berger D, Hiki N, Strecker W, Seidelmann M and Beger HG: Plasma concentrations of endotoxin and antiendotoxin antibodies in patients with multiple injuries: A prospective clinical study. Eur J Surg 162: 853-860, 1996.

14. van Goudoever JB, Corpeleijn W, Riedijk M, Schaart M, Renes I and van der Schoor S: The impact of enteral insulin-like growth factor 1 and nutrition on gut permeability and amino acid utilization. J Nutr 138: 1829S-1833S, 2008.

15. Ozen S, Akisu M, Baka M, Yalaz M, Sozmen EY, Berdeli A and Kultursay N: Insulin-like growth factor attenuates apoptosis and mucosal damage in hypoxia/reoxygenation-induced intestinal injury. Biol Neonate 87: 91-96, 2005.

16. Hunninghake GW, Doerschug KC, Nymon AB, Schmidt GA, Meyerholz DK and Ashare A: Insulin-like growth factor-1 levels contribute to the development of bacterial translocation in sepsis. Am J Respir Crit Care Med 182: 517-525, 2010.

17. Nygren J, Soop M, Thorell A, Efendic S, Nair KS and Ljungqvist O: Preoperative oral carbohydrate administration reduces postoperative insulin resistance. Clin Nutr 17: 65-71, 1998.

18. Sukhanov S, Higashi Y, Shai SY, Vaughn C, Mohler J, Li Y, Song $\mathrm{YH}$, Titterington J and Delafontaine P: IGF-1 reduces inflammatory responses, suppresses oxidative stress, and decreases atherosclerosis progression in ApoE-deficient mice. Arterioscler Thromb Vasc Biol 27: 2684-2690, 2007.

19. Sun XQ, Fu XB, Zhang R, Lu Y, Deng Q, Jiang XG and Sheng ZY: Relationship between plasma $\mathrm{D}(-)$-lactate and intestinal damage after severe injuries in rats. World J Gastroenterol 7: 555-558, 2001.

20. Sheedy JR, Wettenhall RE, Scanlon D, Gooley PR, Lewis DP, McGregor N, Stapleton DI, Butt HL and De Meirleir KL: Increased d-lactic acid intestinal bacteria in patients with chronic fatigue syndrome. In Vivo 23: 621-628, 2009.

21. Haas V, Büning C, Buhner S, von Heymann C, Valentini L and Lochs $\mathrm{H}$ : Clinical relevance of measuring colonic permeability. Eur J Clin Invest 39: 139-144, 2009.

22. Akscyn RM, Franklin JL, Gavrikova TA and Messina JL: Polytrauma-induced hepatic stress response and the development of liver insulin resistance. Biochim Biophys Acta Mol Basis Dis 1863: 2672-2679, 2017.

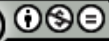

This work is licensed under a Creative Commons Attribution-NonCommercial-NoDerivatives 4.0 International (CC BY-NC-ND 4.0) License. 